\title{
EDUCAÇÃO AMBIENTAL: SCRATCH COMO FERRAMENTA PEDAGÓGICA NO ENSINO DE SANEAMENTO BÁSICO
}

\author{
Aline Marcelino dos Santos Silva, IF Fluminense Campus Campos-Centro \\ alinemarcelino@zipmail.com.br \\ Deiz Amara Silva de Souza Moraes, IF Fluminense Campus Campos-Centro \\ deizamara@hotmail.com \\ Silvia Cristina Freitas Batista, IF Fluminense Campus Campos-Centro \\ silviac@iff.edu.br
}

\begin{abstract}
RESUMO
A falta de cuidados com o saneamento básico pode acarretar diversos problemas ambientais e de saúde. Entende-se, portanto, que é de fundamental importância que a conscientização sobre esses cuidados seja discutida desde a infância. Nesse contexto, o presente artigo analisa a contribuição de objetos de aprendizagem (OA), desenvolvidos no ambiente de programação Scratch, ao serem utilizados como ferramentas pedagógicas para o ensino de Saneamento Básico no $5^{\circ}$ ano do Ensino Fundamental. Para tanto, foi realizado um estudo de caso em uma escola pública do município de Campos dos Goytacazes/RJ, utilizando os três OA produzidos. Como fundamentação teórica adotou-se a teoria vygotskyana. Para a avaliação da estratégia pedagógica adotada, foram utilizadas listas de exercícios de pré e pós-teste, observação e questionário. Os dados foram analisados e mostraram boa aceitação dos alunos aos OA e à proposta da aula.
\end{abstract}

Palavras-chave: scratch, objetos de aprendizagem, saneamento básico, processo de ensino e aprendizagem.

\section{ENVIRONMENTAL EDUCATION: SCRATCH AS A PEDAGOGICAL TOOL IN BASIC SANITATION TEACHING}

\begin{abstract}
The lack of care with sanitation can lead to several health and environmental problems. It is understood, therefore, that it is of fundamental importance that awareness of such care is discussed since childhood. In this context, this paper analyzes the contribution of Learning Objects (LO), developed in the Scratch programming environment, when used as pedagogical tools for Basic Sanitation teaching in 5th year of elementary school. Thus, a case study of a public school in the city of Campos dos Goytacazes/RJ using the three LO was performed. As a theoretical framework adopted the Vygotsky's theory. Lists of exercises pre and post-testing, observation and questionnaire were used to evaluate the teaching strategy adopted. Data were analyzed and showed good acceptance of students to the LO and the proposed class.
\end{abstract}

Keywords: scratch, learning objects, sanitation teaching, learning process.

\section{Introdução}

Segundo Guimarães, Carvalho e Silva (2007, p.1), na perspectiva da Organização Mundial de Saúde (OMS), "saneamento é o controle de todos os fatores do meio físico 
do homem, que exercem ou podem exercer efeitos nocivos sobre o bem estar físico, mental e social". A conscientização e a sensibilização da população quanto aos problemas relacionados à falta de saneamento básico são fundamentais para preservação do meio ambiente e melhoria da qualidade de vida das pessoas (RIBEIRO; ROOKE, 2010). Entende-se que, por meio da escola, o aluno pode desenvolver essa sensibilização e ser um formador ambiental no meio em que vive.

Nesse contexto, as Tecnologias Digitais (TD) podem trazer contribuições ao favorecerem experimentações e investigações. Como defendido por Rodrigues e Colesanti (2008), as tecnologias implicam mudanças de atitudes, valores e comportamentos, ao aproximarem aspectos pedagógicos e necessidades das novas gerações. Dessa forma, as mudanças possibilitadas pelas tecnologias são importantes para o desenvolvimento de trabalhos na área de Educação Ambiental.

Diante desse cenário, promoveu-se uma pesquisa que teve por objetivo investigar a contribuição de objetos de aprendizagem ${ }^{1}$ (OA) desenvolvidos no ambiente de programação Scratch, ao serem utilizados como ferramentas pedagógicas para o processo de ensino e aprendizagem do conteúdo de Saneamento Básico, como parte da Educação Ambiental.

Scratch é um projeto do grupo Lifelong Kindergarten do Media Lab do Massachusetts Institute of Technology (MIT). Trata-se de uma linguagem de programação projetada para fins educacionais, que permite que programas sejam estruturados como blocos de montar (MIT, s.d.).

No ambiente Scratch, foram desenvolvidos três OA direcionados ao estudo de Saneamento Básico: um jogo, um quiz e uma história. Tais recursos foram utilizados em um estudo de caso promovido em uma turma do $5^{\circ}$ ano do Ensino Fundamental de uma escola municipal de Campos dos Goytacazes/RJ. Com o referido estudo buscou-se verificar a percepção dos alunos sobre a proposta pedagógica utilizada, apoiada pelos OA desenvolvidos. Como perspectiva teórica, adotou-se a teoria de Vygotsky, focalizando os conceitos de motivação, Zona de Desenvolvimento Proximal e mediação.

Tendo em vista descrever e analisar a pesquisa promovida, caracteriza-se, na seção 2 deste artigo, a linguagem de programação Scratch e apresentam-se os OA desenvolvidos e utilizados no estudo de caso. Na seção 3, relatam-se os procedimentos metodológicos adotados na pesquisa e, na seção 4, são analisados os resultados obtidos. Finalizando, na seção 5, são tecidas algumas considerações sobre a pesquisa realizada.

2. Scratch no contexto da pesquisa

O Scratch é uma linguagem de programação criada no Media Lab do MIT. A mesma permite a criação de histórias, animações, jogos, artes e outras produções, desenvolvendo um trabalho criativo, colaborativo e interativo. O uso dessa linguagem possibilita uma estratégia diferenciada e facilitadora no ensino de conteúdos curriculares, permitindo desenvolver o raciocínio sistemático (PENSAMENTO DIGITAL, 2012).

Um projeto no Scratch é formado por um palco e por diferentes objetos. Os blocos encaixados se referem às ações a serem realizadas pelos objetos, que são executadas em um palco, ou seja, em um plano de fundo (AURELIANO; TEDESCO, 2013).

De acordo com Pinto (2010), algumas das potencialidades do Scratch são: liberdade de criação, criatividade, comunicação e colaboração entre os estudantes, aprendizagem de conceitos escolares partindo de projetos livres e não escolarizados e manipulação de mídias. Tais potencialidades contribuem para o processo de ensino e aprendizagem.

Muitos trabalhos, como o de Marques (2009), Pinto (2010) e Martins (2012), propõem a utilização do Scratch no contexto escolar, no Ensino Fundamental, visando 
estimular a motivação e a criatividade, por meio da formulação e resolução de situações-problema.

Para o ensino de Ciência, especificamente, é possível citar alguns trabalhos, tais como: i) o de Pereira e Sampaio (2008), que descreve a criação de uma simulação, elaborada no Scratch, de um ecossistema, identificando a dependência existente entre os seus componentes bióticos e suas relações, como cadeias e teias alimentares; ii) o de Machado, Ferreira e Coelho (2010), no qual utilizou-se o Scratch para a criação de histórias sobre fenômenos eletrostáticos no cotidiano; iii) o de Souza (2010), que focalizou o conteúdo de genética e imunologia, a partir da utilização de um OA elaborado no Scratch.

Na pesquisa aqui descrita, o ambiente Scratch foi utilizado para o desenvolvimento de três OA direcionados ao estudo de Saneamento Básico: uma história ${ }^{2}$, um quiz ${ }^{3}$ e um jogo ${ }^{4}$. Destaca-se que os referidos OA foram disponibilizados no portal do $\mathrm{Scratch}^{5}$. Os mesmos foram utilizados com os alunos, no estudo de caso promovido, e são apresentados nas subseções seguintes.

2.1 OA história

O primeiro OA desenvolvido foi uma história na qual foram apresentados os tópicos sobre o Saneamento Básico. Foram ressaltados aspectos relacionados à água, ao lixo e ao esgoto. Pretende-se, por meio da história, que o estudante se sensibilize em relação à Educação Ambiental e perceba a importância de exercer seu papel como multiplicador no contexto social em que vive.

A Figura 1 ilustra um trecho inicial da história que conceitua saneamento básico.

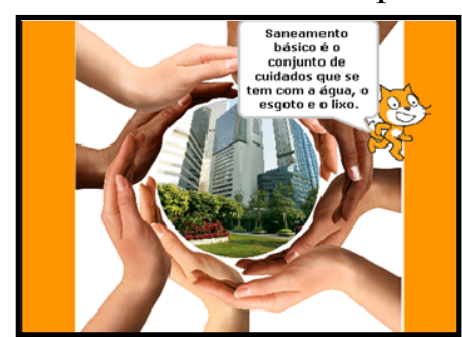

Figura 1 - Tela de apresentação inicial da história

O objetivo da história é introduzir o conteúdo a ser estudado. Na construção da mesma foram utilizadas imagens e textos e um personagem, um gato, chamado Saninho. Inicialmente, o personagem se identifica e convida os estudantes a conhecerem o conteúdo de Saneamento Básico. Os alunos têm a possibilidade de mover o personagem, no decorrer da história, utilizando as setas do teclado do computador.

2.2 OA quiz

O quiz, composto de dez questões com opções de respostas, tem como objetivo avaliar conhecimentos sobre saneamento básico, utilizando questões objetivas.

Após iniciar o quiz, o aluno deverá ler atentamente as mensagens mostradas pelo personagem. Cada pergunta possui três opções de respostas. $\mathrm{O}$ aluno deve responder com a letra correspondente à resposta certa. Caso acerte, recebe uma mensagem de acerto. Caso erre, recebe uma mensagem orientando a rever a sua resposta e tem a possibilidade de tentar outra vez. Após a segunda tentativa, o aluno recebe outra mensagem, que pode ser de acerto ou de erro. O estudante só poderá tentar responder cada pergunta duas vezes.

Sobre a pontuação, o valor depende da quantidade de tentativas. Se o estudante acertar na primeira tentativa receberá dez pontos e na segunda, o valor será de cinco pontos. O aluno poderá observar a pontuação de cada questão no alto da tela, bem como a pontuação total ao término do quiz. 
O quiz também utiliza o mesmo personagem da história para apresentação das perguntas. A movimentação deste é permitida com as setas do teclado do computador.

A Figura 2 mostra a tela de apresentação de uma das perguntas do quiz.

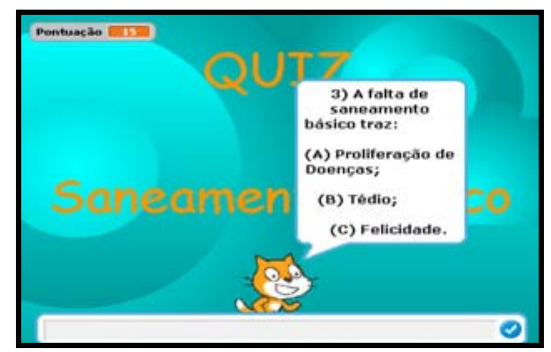

Figura 2 - Tela de apresentação da terceira pergunta do quiz

\subsection{OA jogo Coleta Seletiva}

$\mathrm{O}$ jogo tem por objetivo abordar a importância da reciclagem, de forma lúdica. O mesmo é composto de objetos variados, representando tipos diferentes de lixo, os quais o aluno deverá levar até a lixeira correta de coleta seletiva.

Foram utilizados oito objetos de diferentes materiais enfatizando a variedade de lixo com os quais os estudantes lidam em seu cotidiano. No jogo, foram apresentados quatro tipos de lixeira mais comuns, uma vez que o OA é destinado a alunos do Ensino Fundamental, tendo em vista um contato inicial com o tema coleta seletiva.

$\mathrm{O}$ estudante recebe uma mensagem inicial orientando-o a levar o lixo até a lixeira correta, de acordo com o material, conforme ilustra a Figura 3.

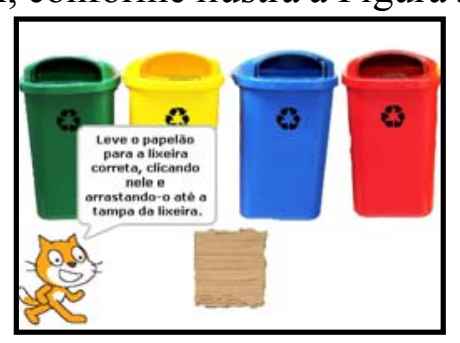

Figura 3 - Tela de apresentação com orientações do jogo Coleta Seletiva

Os OA apresentados foram experimentados em um estudo de caso cujos procedimentos metodológicos são descritos na seção seguinte.

3. Procedimentos metodológicos

A pesquisa realizada teve como objetivo geral investigar a contribuição dos OA elaborados no ambiente de programação Scratch, ao serem utilizados como ferramentas pedagógicas para o processo de ensino e aprendizagem do conteúdo de Saneamento Básico. Para tanto, adotou-se uma pesquisa qualitativa, por meio de um estudo de caso.

Uma turma do $5^{\circ}$ ano do Ensino Fundamental, de uma instituição municipal em Campos dos Goytacazes/RJ, foi selecionada para realizar um estudo de caso. A escolha deste ano de escolaridade se deu pelo fato do currículo desta série apresentar o conteúdo Saneamento Básico, trabalhado nos OA. A escola considerada nesse estudo de caso é a instituição de ensino em que trabalha uma das autoras deste artigo. A mesma conta com um laboratório de informática e possui uma única turma de $5^{\circ}$ ano, na qual se realizou o estudo de caso.

O estudo de caso foi promovido em onze de setembro de 2013 no horário regular de aula dos alunos, com duração de quatro aulas com 50 minutos cada. Os instrumentos de coleta de dados utilizados foram: listas de exercícios de pré-teste e pós-teste, observação e questionário.

$\mathrm{Na}$ primeira aula, cada aluno recebeu, inicialmente, uma lista de exercícios (préteste). O pré-teste apresentou três perguntas: uma dissertativa e duas de múltipla 
escolha. Na primeira pergunta, procurou-se conhecer o que os estudantes entendiam sobre o conceito de saneamento básico. $\mathrm{Na}$ segunda, os alunos deveriam assinalar uma opção de resposta que correspondesse à importância do saneamento básico. Na última pergunta, os alunos deveriam assinalar a opção correspondente à consequência da falta das condições de saneamento básico.

Após o pré-teste, o OA história foi apresentado. Nas duas aulas seguintes, os alunos utilizaram o quiz e o jogo Coleta Seletiva, nessa ordem. A utilização do quiz foi realizada após os alunos lerem as regras do mesmo, que foram entregues de forma impressa.

$\mathrm{Na}$ quarta aula, os estudantes responderam à lista de exercícios referente ao pósteste e a um questionário investigativo sobre o perfil da turma e sobre a aula e os recursos utilizados. O pós-teste visou verificar a compreensão dos conteúdos de Saneamento Básico e incluiu questões semelhantes às respondidas no pré-teste. No pósteste foi proposta a elaboração de dois desenhos (questões 1 e 2), que deveriam retratar a importância do saneamento básico, correspondendo, assim, à questão 2 do pré-teste.

Além disso, o pós-teste apresentou duas questões discursivas, questões 3 e 4 . A questão 3, "De que o saneamento básico cuida?", é correspondente à questão 1 do préteste. A questão 4 "Com a falta de saneamento básico, o que pode acontecer com a vida das pessoas e com o meio ambiente?" é correspondente à questão 3 do pré-teste.

Em relação ao questionário, perguntou-se no item Perfil, o sexo e a idade dos estudantes. Em relação à aula e aos recursos utilizados, foram propostas cinco questões, sendo três de múltipla escolha e duas discursivas. Dentre as questões de múltipla escolha estão: "Você já sabia o que era saneamento básico? Se você já sabia o que era saneamento básico, como ficou sabendo deste assunto?", "Você gostou da aula?", "De qual programinha você mais gostou?". Ao responderem sobre o que mais gostaram da aula, foi proposto aos alunos que justificassem suas respostas, na mesma questão. As questões discursivas foram: "O que mais gostou da aula?" e "O que você acha que poderia melhorar nos programinhas que utilizou?".

A análise das respostas objetivas dos questionários foi feita a partir da organização dos dados em gráficos e tabelas. $\mathrm{Na}$ análise das questões discursivas foi utilizada a técnica da análise de conteúdo de Bardin.

Segundo Franco (2008), a análise de conteúdo utiliza a mensagem, que pode ser verbal (oral ou escrita), gestual, silenciosa, figurativa, documental, ou diretamente provocada (FRANCO, 2008, p. 12). Para realizar a análise de conteúdo, inicialmente realizou-se uma leitura das respostas dos questionários, chamada por Bardin, de "leitura flutuante". Esta é uma leitura superficial dos textos e tem por objetivo conhecer as mensagens apresentadas. A partir da leitura das respostas discursivas, foram elaboradas categorias e as mensagens foram classificadas segundo as mesmas.

4. Resultados e discussão

Nesta seção apresenta-se a análise do estudo de caso realizado com os alunos do $5^{\circ}$ ano do Ensino Fundamental.

Ao iniciar a experiência pedagógica, aplicou-se o pré-teste aos alunos. A seguir, a turma composta por 17 estudantes foi dividida em dois grupos. $\mathrm{O}$ primeiro grupo, com oito alunos, foi, então, levado para o laboratório de informática. Posteriormente, o mesmo foi feito com o outro grupo, com nove alunos. O laboratório nunca havia sido utilizado e os alunos estavam curiosos em utilizá-lo.

Os alunos foram orientados a iniciar o uso do OA história. Após esta etapa, os mesmos foram apresentados ao quiz. Os estudantes estavam motivados e quiseram repetir esta atividade, a fim de acertarem mais perguntas. Por fim, propôs-se o jogo, no qual os alunos verificaram seus conhecimentos sobre coleta seletiva. O OA jogo 
proporcionou bastante entusiasmo e esta atividade também foi repetida pelos alunos. Percebeu-se a motivação dos estudantes ao utilizar os OA. A motivação, para Vygotsky, é um fator necessário no processo de ensino e aprendizagem, pois esta é uma função psicológica. Como defendido por Alves (2013), o indivíduo pode se sentir motivado ao interagir e receber estímulos, e isso pode favorecer a ocorrência de aprendizagens.

Ao fim da utilização dos OA, no laboratório de informática, os estudantes retornaram à sala de aula, onde responderam ao pós-teste e ao questionário de avaliação da aula.

A seguir, são analisados os resultados do pré e pós-teste e os dados do questionário respondidos pelos estudantes.

A primeira questão do pré-teste e a terceira do pós-teste eram discursivas e focalizavam o conceito de saneamento básico. As respostas dessas questões permitiram a identificação das categorias apresentadas na Tabela 1. Os dados apresentados na referida tabela indicam o percentual que cada categoria representa do total de respostas do pré e pós-teste.

Tabela 1: Classificação das respostas das questões 1 do pré-teste e 3 do pós-teste

\begin{tabular}{l|c|c}
\hline \multicolumn{1}{c|}{ Categorias de Respostas } & Pré-teste (\%) & Pós-teste (\%) \\
\hline Relacionadas ao tratamento do lixo & 46 & 33,3 \\
\hline Relacionadas ao cuidado com a saúde & 19 & 13,3 \\
\hline Relacionadas ao cuidado com o meio ambiente & 23 & 13,3 \\
\hline Relacionadas ao tratamento do esgoto & 12 & 33,3 \\
\hline Relacionadas ao cuidado com a água & 0 & 6,8 \\
\hline
\end{tabular}

As categorias criadas permitem analisar a visão dos estudantes sobre o conceito de saneamento básico antes e após a realização do estudo de caso.

Os dados da Tabela 1 indicam que os conhecimentos relacionados ao conceito de saneamento básico foram ampliados, devido à diversificação das respostas apresentas no pós-teste.

A Figura 4 mostra o gráfico produzido a partir das respostas dos alunos do pré-teste sobre a segunda questão “Qual a importância do saneamento básico?”.

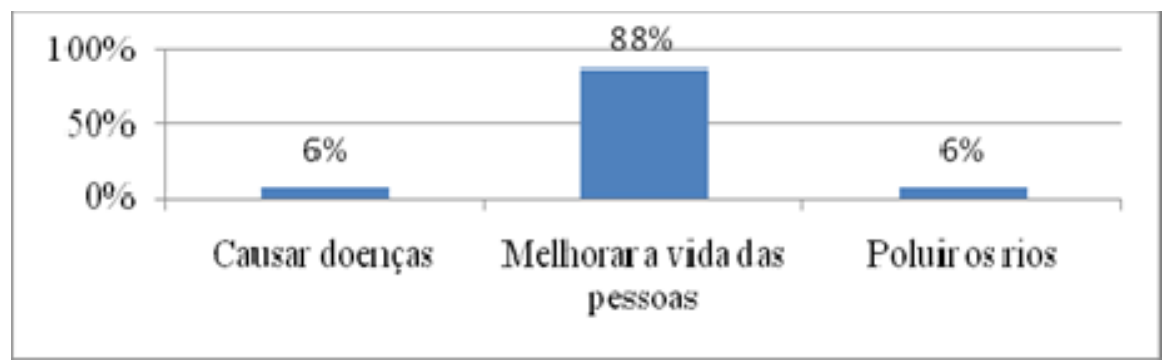

Figura 4: Gráfico das respostas da segunda questão do pré-teste

Observou-se o domínio do conteúdo de grande parte dos alunos, a partir das respostas da segunda questão do pré-teste, pois $88 \%$ dos estudantes demonstraram compreender que o saneamento básico é importante para melhorar a vida das pessoas.

Tais respostas podem ser comparadas aos desenhos elaborados pelos alunos nas questões 1 e 2 do pós-teste. Os dois desenhos demonstraram a importância do saneamento básico para o bem-estar da população. Ao comparar as respostas do préteste da segunda questão com os desenhos elaborados no pós-teste, foi possível verificar uma melhora sobre a compreensão da importância do saneamento básico.

As Figuras 5 e 6 apresentam os desenhos de um aluno representando uma cidade limpa e outra com a falta de saneamento básico. 


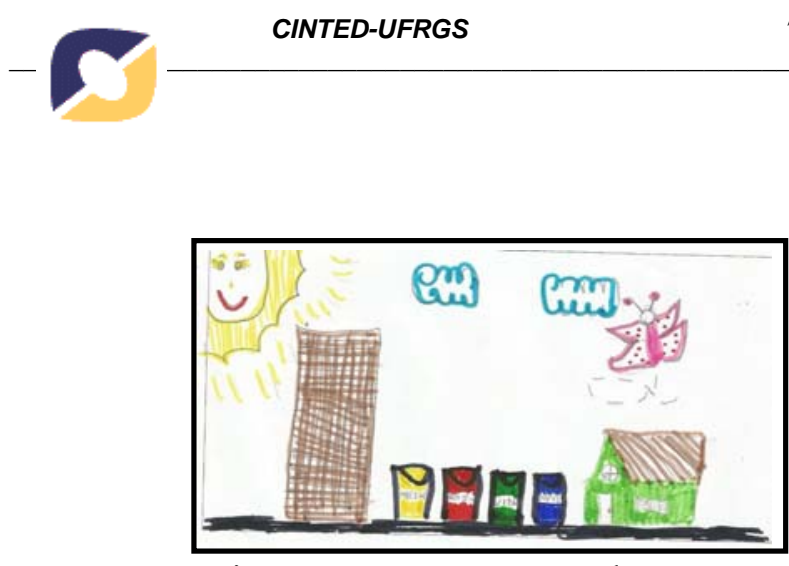

Figura 5 - Representação de uma cidade limpa

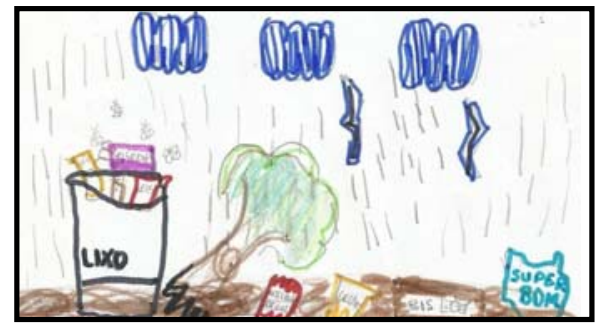

Figura 6 - Representação de uma cidade com a falta de saneamento básico

A questão 3 do pré-teste e a 4 do pós-teste focalizavam as consequências da falta de saneamento básico. Importante destacar que, de acordo com o Sistema Nacional de Informações sobre Saneamento (SNIS) 2010, apenas 53,5\% da população urbana brasileira tem acesso à coleta e $37,9 \%$ ao tratamento de esgotos, ocasionando, desta forma, a contaminação de rios, mananciais, praias e solo. Consequentemente, a saúde da população fica prejudicada, em decorrência das doenças geradas pela falta de tratamento de água e esgoto (TRATA BRASIL, 2012).

A Tabela 2 apresenta os resultados do pré-teste e pós-teste referentes ao questionamento sobre as consequências da falta de saneamento básico.

Tabela 2: Resultados das questões 3 do pré-teste e 4 do pós-teste

\begin{tabular}{c|c|c}
\hline Listas de exercícios & Pré-teste (\%) & Pós-teste (\%) \\
\hline Acertos & 88 & 100 \\
\hline
\end{tabular}

Em relação à Tabela 2, as respostas do pré-teste sobre as conseqüências da falta de saneamento básico também confirmaram o domínio do conteúdo por muitos alunos da turma. Um percentual de $88 \%$ dos alunos afirmou que a falta de saneamento básico pode trazer doenças, sendo esta a resposta correta de acordo com as alternativas propostas. A pergunta equivalente no pós-teste foi respondida corretamente por todos os alunos, evidenciando uma compreensão adequada sobre o que a falta de saneamento básico pode trazer. Entende-se, assim, que houve um avanço sobre o entendimento do conteúdo.

É possível afirmar que o processo de ensino e aprendizagem no estudo de caso contribuiu para a criação da ZDP. Para entender o termo Zona de Desenvolvimento Proximal (ZDP), criado por Vygotsky, é preciso conhecer os termos nível de desenvolvimento real e nível de desenvolvimento potencial. De acordo com Rego (2010), o nível de desenvolvimento real é aquilo que a criança é capaz de fazer de forma autônoma, e o nível de desenvolvimento potencial é aquilo que ela realiza em colaboração com os outros elementos do seu grupo social. A distância entre esses dois níveis caracteriza o que Vygotsky denominou Zona de Desenvolvimento Proximal (ZDP). Esta define as funções que a criança será capaz de realizar, mas que ainda estão em processo de maturação (REGO, 2010).

Durante o estudo de caso, os estudantes utilizaram os OA em colaboração com os colegas e sob a intervenção das professoras, duas primeiras autoras deste artigo. Este processo de colaboração pode ser definido como o nível de desenvolvimento potencial. Ao realizar o pós-teste, verificou-se a elaboração de desenhos e um aumento no número de acertos, demonstrando o nível de desenvolvimento real dos estudantes.

Ao finalizarem a resolução do pós-teste, os estudantes responderam a um questionário que buscou conhecer o perfil dos alunos e a visão dos mesmos sobre a estratégia da aula.

A turma era composta por 17 alunos, sendo 11 do sexo masculino. A média de idade dos alunos era de 10 anos. 
Ao analisar a aula, $88 \%$ dos alunos mencionaram que já tinham conhecimento sobre o conteúdo. Os $12 \%$ que desconheciam equivalem ao mesmo número de alunos que responderam incorretamente às questões 2 e 3 do pré-teste, assim, tais respostas podem ser atribuídas ao desconhecimento destes alunos.

Ao serem questionados sobre a aula, todos os alunos responderam que gostaram da mesma. Neste sentido, a aprovação da estratégia da aula pelos alunos é coerente com a motivação demonstrada por meio das respostas dos alunos e observações.

A utilização dos $\mathrm{OA}$ foi o que a maioria dos alunos mais gostou na aula, o que destaca o papel desses recursos como instrumentos mediadores, que realizam uma intervenção no processo de ensino e aprendizagem. Os OA proporcionaram um tipo de mediação, chamada mediação digital por Garcia (2006). O fato de serem recursos digitais contribui para a motivação, pois os estudantes se sentem mais próximos da realidade em que vivem (GARCIA, 2006). Em relação à turma deste estudo de caso, observou-se tal proximidade com a realidade dos estudantes a partir do conhecimento prévio do perfil da turma por parte de uma das autoras deste artigo, que foi professora da turma em estudo.

Sobre os OA utilizados, a maior parte dos alunos respondeu não precisar de melhorias, mas alguns apresentaram sugestões. Em relação à história, os alunos sugeriram colocar mais brincadeiras e maior tempo de leitura. No jogo, sugeriram maior interação e aumentar o número de lixeiras. No quiz, também sugeriram maior interação e maior número de perguntas. Tais sugestões ainda não foram implementadas, mas ressalta-se que os $\mathrm{OA}$ poderão ser alterados no próprio site em que foram disponibilizados.

Ao analisar o estudo de caso desenvolvido, verificou-se que as ações realizadas colaboraram para a aprendizagem dos estudantes. Vygotsky (2007) descreve a mediação como sendo o processo de intervenção de um elemento intermediário numa relação, que deixa de ser direta e passa a ser mediada por esse elemento. A mediação proporcionada pelos OA contribuiu para a motivação dos alunos, que é um fator necessário ao processo de ensino e aprendizagem.

Por meio do estudo de caso, foram apresentadas condições para o desenvolvimento do estudante, à medida que este interagia com os instrumentos e se relacionava com as professoras e colegas de classe. Assim, destaca-se não só o papel mediador dos OA, mas também o das professoras e dos colegas, que possibilitou a retirada de dúvidas e a troca de conhecimentos. Todas as contribuições deste estudo, portanto, favoreceram a criação da ZDP, possibilitando que os alunos realizassem, corretamente e sozinhos, atividades que anteriormente não eram assim realizadas.

Verifica-se, desta forma, que a proposta pedagógica foi importante para o processo de ensino e aprendizagem do conteúdo em estudo e que os alunos apresentaram percepções positivas a respeito da mesma.

5. Considerações Finais

Foi possível observar a boa aceitação dos OA pelos estudantes. O ambiente de programação Scratch é uma ferramenta pedagógica que pode colaborar para o processo de ensino e aprendizagem dos conceitos relacionados ao Saneamento Básico, ao permitir o desenvolvimento de recursos que podem favorecer a motivação. Além disso, pode contribuir para o desenvolvimento da ZDP do educando no processo de ensino e aprendizagem.

Ressalta-se que outra forma muito importante de utilização do ambiente Scratch é o desenvolvimento de recursos pelos próprios alunos. Isso envolveria, além de conhecimentos sobre o assunto a ser abordado, o desenvolvimento do raciocínio lógico necessário para a programação. No entanto, tal atividade é mais complexa de ser 
desenvolvida por demandar mais tempo para a preparação dos alunos e, portanto, não foi considerada nessa pesquisa.

A mediação digital foi outro aspecto proporcionado pelos OA. A mediação humana foi observada nas relações dos professores e colegas de classe. Tanto a mediação digital quanto a humana atuam na ZDP dos alunos.

Algumas dificuldades foram encontradas em relação à elaboração dos $\mathrm{OA}$ e à instalação do ambiente de programação Scratch. As dificuldades foram solucionadas por meio de pesquisas. Sentiu-se a necessidade de encontrar tutoriais ou manuais mais aprofundados sobre a execução do programa.

Como estudos futuros pretende-se aprimorar os OA de acordo com as sugestões de alunos e realizar estudos de caso semelhantes ao descrito com outros grupos de alunos. Em virtude do pequeno número de trabalhos sobre Scratch no Ensino de Ciências e da importância dos mesmos, objetiva-se, também, desenvolver e experimentar novos OA para o estudo de temas de Ciências, em outros anos de escolaridade. A utilização do Scratch por alunos, para o desenvolvimento de recursos, também poderá ser investigada.

Notas de Texto

${ }^{1}$ Os OA, segundo Macêdo et al. (2007), são recursos que têm por objetivo apoiar a construção do conhecimento. Os mesmos podem ser criados em diferentes mídias ou formatos e podem ser simples, como uma apresentação de slides, ou complexos, como uma simulação (MACÊDO et al., 2007).

${ }^{2}<\mathrm{http}: / /$ scratch.mit.edu/projects/15047021/>.

${ }^{3}<$ http://scratch.mit.edu/projects/15047143/>.

${ }^{4}<$ http://scratch.mit.edu/projects/15047076/>.

${ }^{5}<\mathrm{http}: / /$ scratch.mit.edu/>.

Referências Bibliográficas

ALVES, I. da S. Motivação no contexto escolar: novos olhares. 2013. 55p. Monografia (Curso de Pedagogia) - Faculdade Capixaba da Serra, Espírito Santo. 2013. Disponível em: $<$ http://serra.multivix.edu.br/wp-content/uploads/2013/09/ironete_02. pdf $>$. Acesso em: 18 out. 2013.

AURELIANO, V. C. O.; TEDESCO, P. C. de A. R. Avaliando o uso do Scratch como abordagem alternativa para o processo de ensino-aprendizagem de programação. In: CONGRESSO DA SOCIEDADE BRASILEIRA DE COMPUTAÇÃO, 32., 2012, Curitiba. Anais... Curitiba: UFPR, 2013. p. 1-10.

FRANCO, M. L. P. B. Análise de conteúdo. 3. ed. Brasília: Líber Livro Editora, 2008.

GARCIA, S. C. Objetos de aprendizagem: investindo na mediação digital do conhecimento. In: CÍRCULO DE ESTUDOS LINGUÍSTICOS DO SUL, 7. 2006, Pelotas. Anais... Pelotas: UCPel/UFPel, 2006. p. 1-8. Disponível em: $<$ http://www.celsul.org.br/Encontros/07/dir2/17.pdf >. Acesso em: 18 out. 2013. GUIMARÃES, A. J. A.; CARVALHO, D. F. de; SILVA, L. D. B. da. Saneamento básico. S. 1., 2007, 9 p. Apostila do Instituto de Tecnologia/Departamento de Engenharia - Universidade Federal Rural do Rio de Janeiro. Disponível em: $<$ http://www.ufrrj.br/institutos/it/deng/leonardo/downloads/APOSTILA/Apostila\%20IT \%20179/Cap\%201.pdf>. Acesso em: 17 jun. 2013.

MACÊDO, L. N. de et al. Desenvolvendo o pensamento proporcional com o uso de um objeto de aprendizagem. In: PRATA, C. L.; NASCIMENTO, A. C. A de (Org.). Objetos de aprendizagem: uma proposta de recurso pedagógico. Brasília: MEC, SEED, 2007. p. 17-26.

MACHADO, G. R.; FERREIRA, A. J.; COELHO, S. M. Informática educativa: uma possibilidade para auxiliar o Ensino de Ciências nas Séries Iniciais. In: SALÃO DE 
INICIAÇÃO CIENTÍFICA, 11. 2010, Porto Alegre. Anais... Porto Alegre: PUCRS, 2010. p. 1252-1255. Disponível em: $<$ http://www.pucrs.br/edipucrs/XISalaoIC/Ciencias_Humanas/Educacao/83019GISELERAMIRESMACHADO.pdf >. Acesso em: $\overline{7} \mathrm{dez} .2013$.

MARQUES, M. T. P. M. Recuperar o engenho a partir da necessidade, com recurso às tecnologias educativas: contributo do ambiente gráfico de programação Scratch em contexto formal de aprendizagem. 2009. 219 p. Dissertação (Mestrado em Tecnologias Educativas) - Faculdade de Psicologia e de Ciências da Educação, Universidade de Lisboa, Lisboa. 2009.

MARTINS, A. R. de Q. Usando o Scratch para potencializar o pensamento criativo em crianças do Ensino Fundamental. 2012. 114p. Dissertação (Mestrado em Educação) - Universidade de Passo Fundo, Passo Fundo. 2012.

MIT - MASSACHUSETTS INSTITUTE OF TECHNOLOGY. About Scratch. s.d. Disponível em: <http://scratch.mit.edu/about/>. Acesso em: 18 out. 2013.

PENSAMENTO DIGITAL. Iniciação à programação. Disponível em: $<$ http://oficinas.pensamentodigital.org.br/apostila_iniciacao_programacao.pdf $>$. 2012. Acesso em: 21 set. 2013.

PEREIRA, A. S. T.; SAMPAIO, F. F. AVITAE: desenvolvimento de um ambiente de modelagem computacional para o ensino de biologia. Ciências \& Cognição, v. 13, n. 2, p. 51-70, jul. 2008.

PINTO, A. S. Scratch na aprendizagem de matemática no $1^{\circ}$ Ciclo do Ensino Básico: estudo de caso na resolução de problemas. 2010. 128p. Dissertação (Mestrado em Estudos da Criança - Tecnologias de Informação e Comunicação) - Universidade de Minho, Guimarães. 2010.

REGO, T. C. Vygotsky: uma perspectiva histórico-cultural da educação. 21. ed. Petrópolis, RJ: Vozes, 2010. 138 p.

RIBEIRO, J. W.; ROOKE, J. M. S. Saneamento básico e sua relação com o meio ambiente e a saúde pública. 2010. 36 p. Trabalho de conclusão de curso (Curso de Especialização em Análise Ambiental) - Universidade Federal de Juiz de Fora, Juiz de Fora, 2010. Disponível em: <http://www.ufjf.br/analiseambiental/files/2009/11/TCCSaneamentoeSa\%C3\%BAde.pdf>. Acesso em: 4 nov. 2013.

RODRIGUES, G. S. de S. C.; COLESANTI, M. T. de M. Educação ambiental e as novas tecnologias de informação e comunicação. Revista Sociedade \& Natureza, Uberlândia, v. 20, n. 1, p. 51-66, jun. 2008.

SOUZA, N. F. L. de L. e. Contribuições de uma proposta multimídia baseada no enfoque Ciência, Tecnologia e Sociedade para o ensino das bases genéticas e imunológicas do sistema sanguíneo ABO humano. 2010. 110 p. Dissertação (Mestrado em Ensino de Ciências e Matemática). Pontífice Universidade Católica de Minas Gerais. Belo Horizonte: 2010.

TRATA BRASIL. Ranking do Saneamento - Instituto Trata Brasil: nova metodologia e resultados. 2012. Disponível em: $<$ http://www.tratabrasil.org.br/datafiles/uploads/pdfs/relatorio-ranking.pdf $>$. Acesso em: 20 fev. 2013.

VYGOTSKY, L. S. A Formação Social da Mente: o desenvolvimento dos processos psicológicos superiores. 7. ed. São Paulo: Martins Fontes, 2007. 